\title{
Inter-relationship and path analysis of different traits of two line hybrid in rice (Oryza sativa L.)
}

\author{
Pardeep Kumar*, M. K. Nautiyal and Kuldeep Kumar
}

Department of Genetics \& Plant Breeding, G. B. Pant University of Agriculture and Technology, Pantnagar263145 (Uttarakhand), INDIA

*Corresponding author. E-mail: pardeepkumar656@gmail.com

Received: February 28, 2016; Revised received: August 4, 2016; Accepted: November 4, 2016

\begin{abstract}
The present study was undertaken with the objective to determine the nature and magnitude of variability, degree of association between yield and it's component characters and their direct and indirect effects on grain yield in rice. The experiment was conducted on rice in year 2013-14 at Borlaug Crop Research Center of G. B. Pant University of Agriculture and Technology, Pantnagar, Uttarakhand. All the traits had positive correlation to seed yield per plant of rice except days to flowering at genotypic level and at the phenotypic level. At phenotypic level panicle length $(0.2145)$ and harvest index $(0.4713)$ had highly significant level and positive correlation to seed yield per plant. Grain number per panicle (0.1550) and panicle number per plant $(0.1398)$ showed positive and level of significant correlation with seed yield per plant. The days to flowering $(-0.1879)$ have highly significant level with negative correlation to seed yield per plant. Path analysis showed the positive and direct effect on seed yield per plant at genotypic and phenotypic level for panicle number per plant ( 0.393 and 0.380 respectively), panicle length ( 0.236 and 0.198$)$, grain number per panicle $(0.646$ and 0.112$)$ and harvest index $(0.443$ and 0.448$)$. While days to flowering $(-0.175$ and -0.167$)$ and plant height $(-0.037$ and -0.008$)$ had negative direct effect. The traits which showed positive correlation and positive direct effect on seed yield per plant can be used to increase seed yield for further breeding programs and may be given due importance in selection during rice breeding programme.
\end{abstract}

Keywords: Correlation, Line $\mathrm{X}$ tester, Negative, Positive, Path analysis, Rice

\section{INTRODUCTION}

Rice (Oryza sativa L.) is the most important staple food crop for half of the world's population. The Green Revolution technology developed at the International Rice Research Institute (IRRI) in the 1960s increased world rice production. The hybrid rice is being the new answer to the growing hunger of world population; by the way of its elevated yield potential, agronomic performance and disease resistance. Genetic variability, correlation and path coefficients are pre-requisites for improvement of any crop including rice in any trait by selection of superior genotypes (Hassan et al., 2010). The knowledge of the association of various traits with rice yield and their mutual-relationship of the traits is essential in improving the selection efficiency and crop yield. Traits interrelationship derived by correlation coefficient, given the basis for selecting the desirable plant, aiding in evaluation of relative influence of various component characters on grain yield. Path coefficient analysis discerns correlation into direct and indirect effects (Ekka et al. 2011). The most important criteria in any crop improvement programme is the selection of genotypes with all possible desirable yield contributing traits. The knowledge regarding relative contribution of individual traits to yield may be accomplished by correlation studies (Allard, 1960 and
Chaubey et al. 1994). However, simple correlation does not provide the adequate information about the contribution of each factor towards yield. Therefore, the technique of path coefficient analysis is utilized to have an idea of direct and indirect contribution of a trait towards the yield (Nandan et al., 2010).

\section{MATERIALS AND METHODS}

The present investigation was carried out at the Borlaug Crop Research Center of G. B. Pant University of Agriculture and Technology, Pantnagar, Uttarakhand (India) in 2014 kharif season. The material used for this study consisted of eighteen thermosensitive genetic male sterile (TGMS) lines and four testers (Table 1).

The eighteen lines were crossed with four testers during kharif season in 2013 using Line X Tester mating design. The resulting 72 cross combinations with 22 parents (lines and testers) grown in randomized complete block design in three replications during the 2014 kharif season. Data were collected from five randomized selected plants from each replication. The traits on which data were collected viz. Days to 50\% flowering, Plant height, Panicle length, Panicle number per plant, Spikelet number per panicle, Grain number per panicle, Per cent spikelet fertility, 1000 grain weight, Harvest index and Grain yield per plant. Genotypic and phenotypic correlation coefficients 
were calculated following by Miller et al. (1958). Path coefficient analysis was estimated according to the method suggested by Dewey and Lu (1959).

\section{RESULTS AND DISCUSSION}

The analysis of variance revealed significant level of variations among all the lines for all the characters studied in rice and same findings observed by Malik and Singh (2013) in rice crop. At genotypic level (Table 2) the days to flowering was positively correlated to the all the characters except harvest index and grain yield per plant in rice while plant height showed negative correlation with panicle number per plant, percent spikeletes fertility, 1000 grain weight and harvest index. Panicle number per plant was positively correlated with days to 50 percent flowering, plant height, percent spikeletes fertility, 1000 grain weight and grain yield per plant while panicle length had positive relationship with days to 50 percent flowering, plant height, spikeletes number per panicle, grain number per panicle, harvest index and grain yield per plant. The result for panicle length was accordance with Hasan et al. (2010). Spikeletes number per panicle positively correlated with days to 50 percent flowering, plant height, panicle length, grain number per panicle, 1000 grain weight and grain yield per plant while grain number per panicle showed positive correlation to all the traits except for panicle number plant and percent spikeletes fertility.
The percent spikeletes fertility percentage had positive correlation with days to 50 percentages flowering, panicle number per plant, harvest index and grain yield per plant while harvest index indicated positive correlation with grain yield per plant, panicle length, grain number per panicle, percent spikeletes fertility and 1000 grain weight. The grain yield per plant was positively correlated with 1000 grain weight, this finding for grain yield per plant were also observed by Ekka et al. (2011) and Akhtar et al. (2011), for harvest index observed by Surek and Beser ( 2013), for days to 50 percent flowering by Reddy et al. (2013) and for percent spikeletes fertility by Kumar et al. (1998).

At phenotypic level (Table 3) days to flowering had high level of significant and negatively correlated to the harvest index and grain yield per plant while plant height was negatively correlated with panicle number per plant, percent spikeletes fertility, 1000 grain weight and harvest index. Panicle number per plant was showed significant level and positively correlated with days to 50 percent flowering, 1000 grain weight and grain yield per plant. Panicle length had high level of significant and positive correlation with plant height, spikeletes number per plant and grain yield per plant. Spikeletes number per panicle was positively and high level of significantly correlated with days to 50 percent flowering, grain number per panicle, panicle length and 1000 grain

Table 1. Details of parents used in the study for correlation and path analysis.

\begin{tabular}{|c|c|c|c|c|}
\hline $\begin{array}{l}\text { S. } \\
\text { N. }\end{array}$ & $\begin{array}{l}\text { TGMS } \\
\text { (code) }\end{array}$ & TGMS Lines & Parentage & Source \\
\hline 1 & TGMS-1 & UPRI-99-70-1 & UPRI 95-140 TGMS / UPRI 95-141 & GBPUAT, Pantnagar \\
\hline 2 & TGMS-2 & UPRI-99-71-1 & UPRI 95-140 TGMS / UPRI 95-150 // UPRI 95-162 & GBPUAT, Pantnagar \\
\hline 3 & TGMS-3 & UPRI-99-71-2 & UPRI 95-140 TGMS / UPRI 95-150 // UPRI 95-162 & GBPUAT, Pantnagar \\
\hline 4 & TGMS-4 & UPRI-99-73-1 & UPRI 95-140 TGMS / IR 36 // IR Basmati & GBPUAT, Pantnagar \\
\hline 5 & TGMS-5 & UPRI-99-73-2 & UPRI 95-140 TGMS / IR 36 // IR Basmati & GBPUAT, Pantnagar \\
\hline 6 & TGMS-6 & UPRI-99-73-3 & UPRI 95-140 TGMS / IR 36 // IR Basmati & GBPUAT, Pantnagar \\
\hline 7 & TGMS-7 & UPRI-99-73-4 & UPRI 95-140 TGMS / IR 36 // IR Basmati & GBPUAT, Pantnagar \\
\hline 8 & TGMS-8 & UPRI-99-74-3 & UPRI 95-140 TGMS / IR BB 21 // IR Basmati & GBPUAT, Pantnagar \\
\hline 9 & TGMS-9 & UPRI-99-79-1 & UPRI 95-140 TGMS / UPRI 95-141 // UPRI 95-162 & GBPUAT, Pantnagar \\
\hline 10 & TGMS-10 & UPRI-99-60-1 & UPRI 95-140 TGMS / UPRI 95-141 & GBPUAT, Pantnagar \\
\hline 11 & TGMS-11 & UPRI-99-72-1 & UPRI 95-140 TGMS / UPRI 95-150 // UPRI 95-161 & GBPUAT, Pantnagar \\
\hline 12 & TGMS-12 & UPRI-99-72-3 & UPRI 95-140 TGMS / UPRI 95-150 // UPRI 95-161 & GBPUAT, Pantnagar \\
\hline 13 & TGMS-13 & UPRI-99-72-4 & UPRI 95-140 TGMS / UPRI 95-150 // UPRI 95-161 & GBPUAT, Pantnagar \\
\hline 14 & TGMS-14 & UPRI-99-74-1 & UPRI 95-140 TGMS / IRBB-21 // IR Basmati & GBPUAT, Pantnagar \\
\hline 15 & TGMS-15 & UPRI-99-74-4 & UPRI 95-140 TGMS / IR BB 21 // IR Basmati & GBPUAT, Pantnagar \\
\hline 16 & TGMS-16 & UPRI-99-75-1 & UPRI 95-140 TGMS / IRBB-21 // UPRI-95-150 & GBPUAT, Pantnagar \\
\hline 17 & TGMS-17 & UPRI-99-78-1 & UPRI 95-140 TGMS / IR 66159-131-4-3-2 & GBPUAT, Pantnagar \\
\hline 18 & TGMS-18 & UPRI-97-60-8 & UPRI 95-140 TGMS / UPRI 95-140-1 & GBPUAT, Pantnagar \\
\hline 19 & Tester & Pant Basmati-1 & Pusa Basmati / IET 12603 (UPR 908-11-1-1-5) & GBPUAT, Pantnagar \\
\hline 20 & Tester & Pant Dhan-4 & UPRI-74-14 (BG 90-2) / IR 262 // Remadja & GBPUAT, Pantnagar \\
\hline 21 & Tester & Pant Dhan-12 & Govind / UPRM 201-1-1 & GBPUAT, Pantnagar \\
\hline 22 & Tester & UPRI-93-287R & MDC 19340 & GBPUAT, Pantnagar \\
\hline
\end{tabular}


Pardeep Kumar et al. / J. Appl. \& Nat. Sci. 8 (4): 2016-2020 (2016)

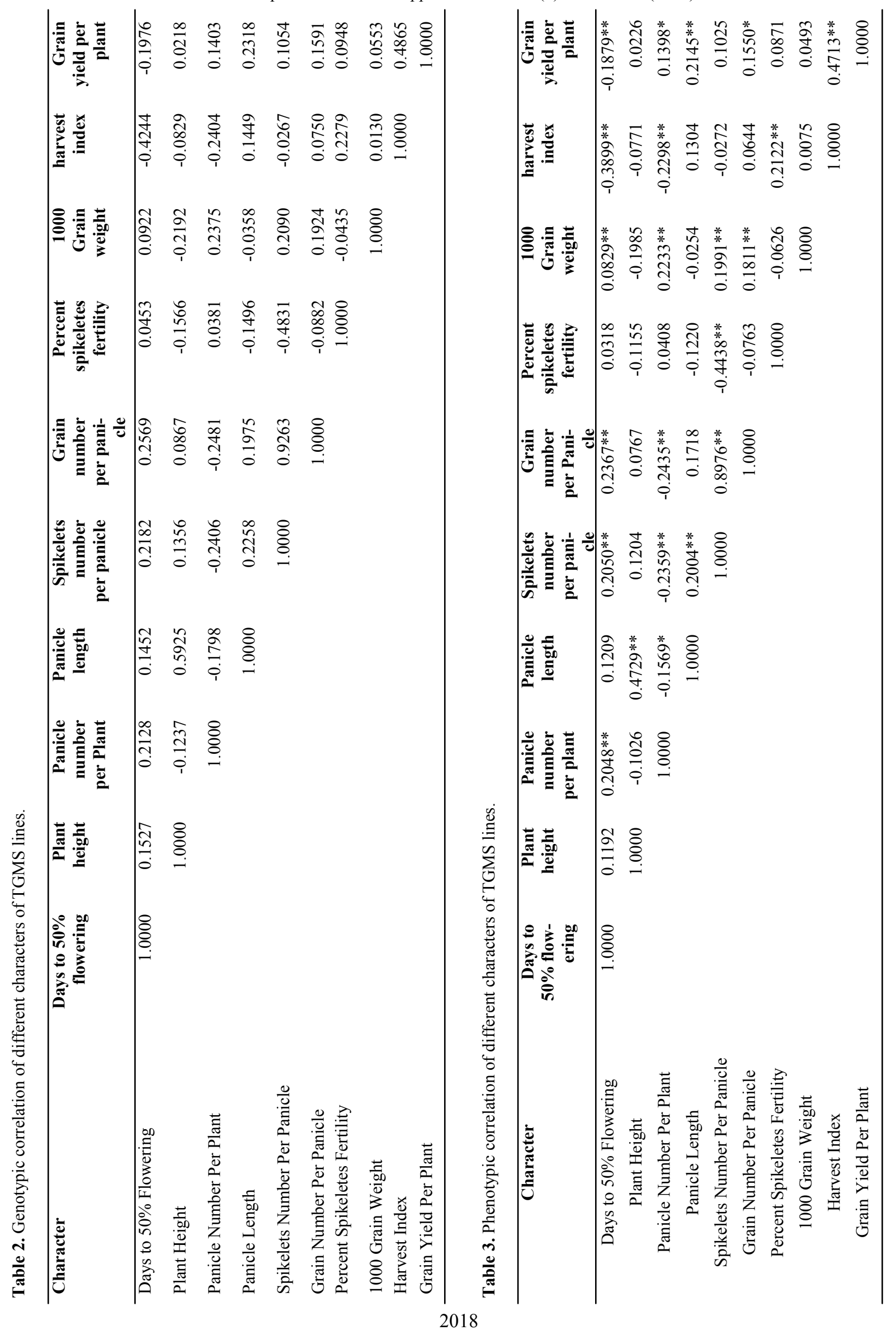


Pardeep Kumar et al. / J. Appl. \& Nat. Sci. 8 (4): 2016-2020 (2016)

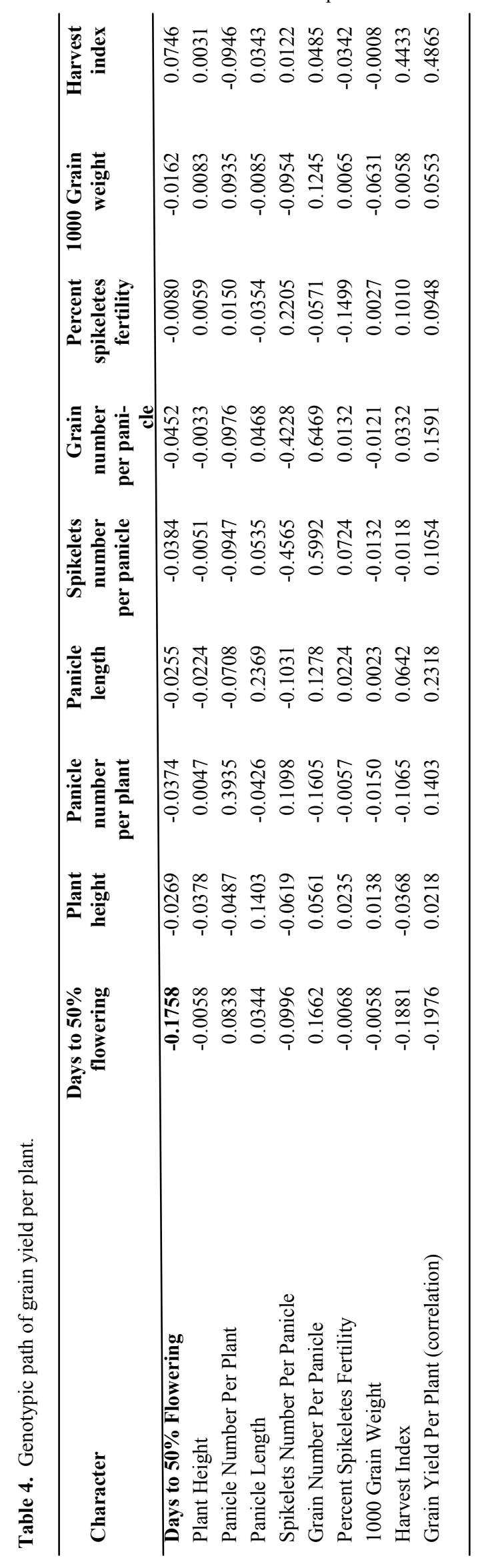

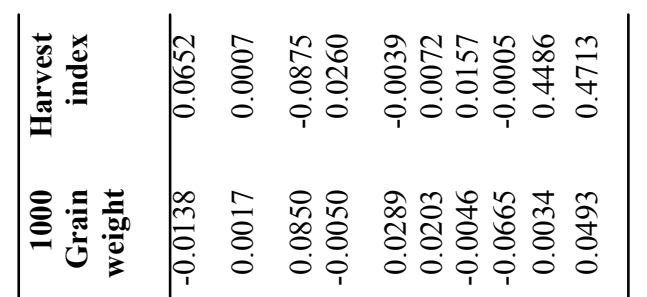

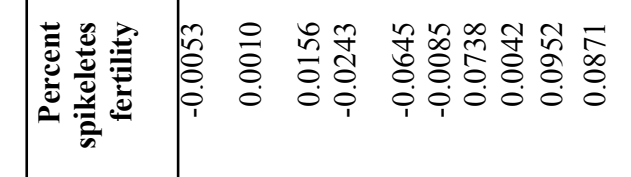

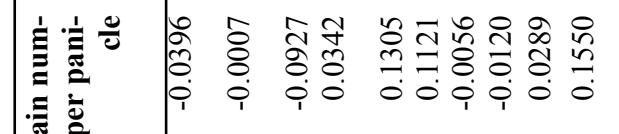

政

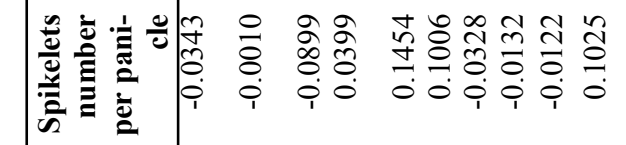

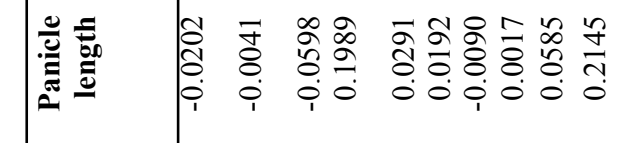

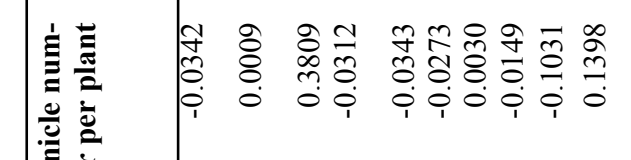

焉

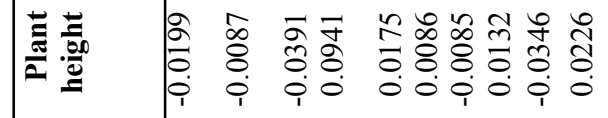

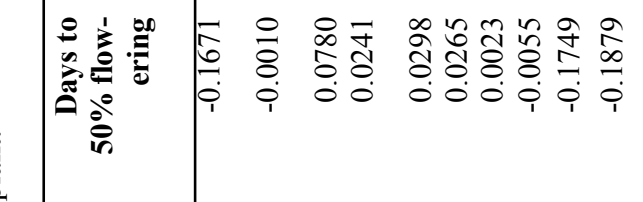

害

竞

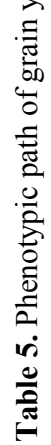


weight while grain number per panicle showed positive and high level of significant correlation with 1000 grain weight, days to 50 percent flowering, Spikeletes Number Per Panicle and significant with grain yield per plant., High level of significant and positive correlation was observed between percent spikeletes fertility and harvest index. The 1000 grain weight also showed the same relation with days to 50 percent flowering, panicle number per plant, spikeletes number per plant and grain number per plant while harvest index with grain yield per plant and percent spikeletes fertility. The grain yield per plant showed high level of significant and positive correlation with harvest index and panicle length.

Path analysis indicated the all the traits were positively correlated to the grain yield per plant except days to flowering. At genotypic level negative direct effect on grain yield per plant observed for days to 50 percent flowering $(-0.1758)$, plant height $(-0.0378)$, spikeletes number per panicle $(-0.4565)$, percent spikeletes fertility $(-0.1499)$ and 1000 grain weight $(-0.0631)$ while positive direct effects of panicle number per plant (0.3935), panicle length $(0.2369)$, grain number per panicle $(0.6469)$ and harvest index (0.4433). The same findings for direct effect on grain yield per plant by different traits also observed by different researchers for panicle number per plant by (Paul and Nanda, 1994; Yadav and Bhushan, 2001), for panicle length (Babu et al., 2012), for grain number per panicle (Islam et al., 2015) and for harvest index (Surek and Beser, 2013). High indirect effect was observed on grain yield per plant of spikeletes number per panicle through percent spikeletes fertility, grain number per panicle. Other traits showed very minor indirect effect on grain yield per plant and the residual effect was 0.7767 .

At phenotypic level the path analysis indicated that (Table -5 ), all the traits had positive direct effect on grain yield per plant except days to flowering, plant height and 1000 grain weight that showed negative direct effect. Spikeletes number per panicle showed high indirect effect on grain yield per plant through grain number per panicle $(0.1305)$ while high negative indirect effect observed on grain yield per plant of plant height through grain number per panicle $(-0.0007)$ while the overall residual effect was 0.7912 .

\section{Conclusion}

The traits panicle number per plant, panicle length, grain number per panicle and harvest index of rice showed high direct effect on grain yield per plant and also showed high positive correlation to the grain yield per plant. Hence in the two line breeding system for hybrid development by incorporation these traits can be break the yield barrier in rice or may be given due importance in selection during rice breeding programme. The correlation and path analysis would be very useful statistic measures for the selection of yield increasing traits.

\section{REFERENCES}

Akhtar, N., Nazir, M.F., Rabnawaz, A., Mahmood, T., Safdar, M. E., Asif, M. and Rehman, A. (2011). Estimation of heritability, correlation and path coefficient analysis in fine grain rice (Oryza sativa L.). The Journal of Animal \& Plant Sciences, 21(4): 660-664

Allard, R.W. (1960). Principles of plant breeding. John Wiley and Sons. Inc. London, pp: 83-108.

Babu, V.R., Shreya, K., Dangi, K.S., Usharani, G. and Shankar, A.S. (2012). Correlation and path analysis studies in popular rice hybrids of India. International J. of Scientific and Res. Pub., 2(3): 1-5

Chaubey, P.K. and Singh, R. (1994). Genetic variability, correlation and path analysis of yield components of rice. Madras Agric. J., 81(9): 468-470

Dewey, D.R. and Lu, K.I. (1959). A correlation and path coefficient analysis of components of created wheat grass seed production. Agronomy Journal, 515-518

Ekka, R.E., Sarawgi, A.K. and Kanwar, R.R. (2011). Correlation and path analysis in traditional rice accessions of Chhattisgarh. J. of Rice Res, 4 (1 \& 2):11-18

Hassan, M.J., Kulsum, M.U., Akter, A., Masuduzzaman, A. S.M. and Ramesha, M.S. (2010). Genetic variability and character association for agronomic traits in hybrid rice (Oryza sativa L.) Bangladesh J. Pl. Breed. Genet, 24(1): 45-51

Islam, M.A., Raffi, S.A., Hossain, M.A. and Hasan, A.K. (2015). Character association and path coefficient analysis of grain yield and yield related traits in some promising early to medium duration rice advanced lines. Int. J. Expt. Agric, 5(1):8-12

Kumar, G. S., Mahadevappa, M. and Rudraradhya, M. (1998). Studies on genetic variability, correlation and path analysis in rice during winter across the locations. Karnataka Journal of Agricultural Science, 11(1): 73-77

Malik, S. and Singh, S. (2013).Combining ability analysis for yield and related traits in rice (Oryza sativa L.). The Bioscan, 8(4): 1417-1420

Miller, P.A., Williams, C., Roginson, H.F. and Comstock, R. E. (1958). Estimates of genotypic and environmental variance and covariance and implication in section. Agronomy Journal, 50: 126-131

Nandan, R. Sweta and Singh, S.K. (2010). Character association and path analysis in rice (Oryza sativa L. ) Genotypes. World Journal of Agricultural Sciences, 6 (2): 201-206

Paul, C.R. and Nanda, J.S. (1994). Path analysis of yield and yield components and construction of selection indices of direct seeded rice: first season. Annual review conference proceedings. National Agriculture Research Institute, Caribbean Agricultural Research and Development Institute, Guyana, 63-71 p.

Reddy, G.E., Suresh B.G., Sravan T. and Reddy, P.A. (2013). Interrelationship and cause-effect analysis of rice genotypes in north east plain zone. The Bioscan, 8(4): 11411144

Surek, H. and Beser, N. (2013). Correlation and path coefficient analysis for some yield-related traits in rice (Oryza sativa L.) under thrace conditions. Turk J Agric., 27:77-83

Yadav, R.S. and Bhushan, C. (2001). Effect of moisture stress on growth and yield in rice genotypes. Ind J Agricult. Res., 2:104-107 